\title{
Paediatrics in Barcelona: highlights from the 2010 ERS Annual Congress
}

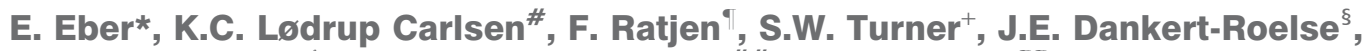 \\ R.I. Ross-Russell ${ }^{f}$, F. Midulla**, P. Aurora ${ }^{\# \#}$ and G. Hedlin ${ }^{\sigma \oplus}$
}

\begin{abstract}
The aim of this update is to describe the paediatric highlights from the 2010 European Respiratory Society Annual Congress in Barcelona, Spain. Abstracts from the seven groups of the Paediatric Assembly (Respiratory physiology, Asthma and allergy, Cystic fibrosis, Respiratory infection and immunology, Neonatology and paediatric intensive care, Respiratory epidemiology and Bronchology) are presented in the context of the current literature.
\end{abstract}

KEYWORDS: Asthma, bronchoscopy, cystic fibrosis, epidemiology, lung function, respiratory infection

$\mathbf{T}$ he 2010 European Respiratory Society (ERS) Congress in Barcelona, Spain, included a large paediatric programme, containing numerous high-quality scientific presentations. As a service to those who could not attend a session or even the whole congress this update will review the highlights of the abstracts presented by the Paediatric Assembly. These abstracts were selected by the chairs from each of the paediatric scientific groups and are discussed in the context of the current literature. Due to the large number of contributions to the congress, the summary cannot be comprehensive, but rather aims to address schemes of new research in major areas of paediatric respiratory medicine.

\section{PAEDIATRIC ASTHMA AND ALLERGY Inflammatory markers}

Breathomics [1], metabolomics [2], biological profiling and exhaled breath analyses $[3,4]$ are used to identify, characterise or classify asthmatic and/or allergic children as well as to understand underlying mechanisms and optimise management. The increasing interest in research in these areas was reflected at the 2010 ERS Congress. Biological profiling of exhaled breath condensate (EBC) was used to characterise virus-induced wheeze [5] and wheezing infants [6]. In the EUROPA study VAN DER SCHEE et al. [5] found that biomarkers could differentiate infants and young children with confirmed versus non-confirmed wheeze, as well as respiratory syncytial virus positive versus negative patients. CARRARO et al. [6] demonstrated that different metabolic profiles could differentiate those with poorly controlled and severe asthma from those with mild asthma. The electronic nose (the "e-nose") was demonstrated as a novel way to profile exhaled products and was found to be feasible to analyse profiles of volatile organic compounds (VOCs) in both infants and school children [7]. VOCs can also be potentially used to identify asthma [8] with eight out of 945 different identified components discriminating between asthmatic and healthy children. Common to these "-omics" studies is still that they are exciting in light of better understanding mechanisms in asthma development and presentation, but that the clinical potential and value has yet to be determined. With ever more sensitive techniques, new biological inflammatory substances are found to be associated with asthma, such as the newly discovered eoxins [9]. Although many of these substances may suggest potential treatment targets for asthma, it is essential to assess whether they are related to asthma specifically (which was found in the case of eoxins) or whether they might also be involved in inflammatory processes of other types of lung diseases.

After more than a decade, many of these questions are well on the way to being answered for exhaled nitric oxide fraction $(F \mathrm{eNO})$. One important issue is whether or not this marker enables us to predict future disease or severity of disease. FRANKLIN et al. [10] investigated FeNO in 105 infants by the single breath method and reassessed the children at $7 \mathrm{yrs}$ of age for wheezing with subsequent categorisation into transient wheezers or persistent wheezers. They

\section{AFFILIATIONS}

*Dept of Paediatrics, University Children's Hospital, Medical University of Graz, Graz, Austria. \#Dept of Paediatrics, Oslo University Hospital and the Faculty of Medicine, University of Oslo, Oslo, Norway.

"Division of Respiratory Medicine, Hospital for Sick Children, Toronto, ON, Canada.

${ }^{+}$Dept of Child Health, University of Aberdeen, Aberdeen,

${ }^{f}$ Dept of Paediatrics, Addenbrooke's Hospital, Cambridge, and

\#\# Dept of Paediatric Respiratory

Medicine, Great Ormond Street Hospital for Children, London, UK. ${ }^{\S}$ Dept of Paediatrics, Atrium Medisch Centrum Parkstad, Heerlen, The Netherlands.

**Dept of Paediatrics, Sapienza University of Rome, Rome, Italy. •Astrid Lindgren Children's Hospital, Karolinska University Hospital, Stockholm, Sweden.

\section{CORRESPONDENCE}

E. Eber

Klinische Abteilung für Pulmonologie und Allergologie, Universitätsklinik für Kinder- und Jugendheilkunde Medizinische Universität Graz

Auenbruggerplatz 34/2

8036 Graz

Austria

E-mail: ernst.eber@medunigraz.at

Received:

Feb 112011

Accepted:

Feb 142011

First published online:

April 82011

European Respiratory Journal

Print ISSN 0903-1936

Online ISSN 1399-3003 
found no significant difference in infant $F$ eNO in children with or without current wheeze and FeNO (in contrast to spirometric values) was not significantly different according to wheezing categories by 7 yrs. Likewise, in a 6-yr follow-up study of infants, CHAWES et al. [11] found no association between FeNO and lung function in infancy or at 6 yrs in the same children, whereas increased FeNO in healthy babies of asthmatic mothers was predictive of transient, but not persistent, wheeze.

\section{Lung function testing}

Lung function testing in paediatric asthma has made important progress in the past few years. With revised reference ranges of lung function parameters [12], the need for population-specific reference values, as well as developmental aspects, have been highlighted, and several of the old, and also some of the new, reference values have been demonstrated to be inappropriate for specific populations [12-14]. Given the vast use of spirometry in every day clinical practice, the relative lack of published longitudinal lung function data in children is a paradox. The usefulness of lung function measurements has been discussed in relation to characterisation and severity of asthma [15-17]. A recent study from London, UK, on the lung clearance index (LCI) showed that children with severe asthma had a higher LCI when compared with age-matched controls [18]. Forced expiratory volume in $1 \mathrm{~s}$ (FEV1), however, was not related to severity of asthma. The authors concluded that LCI appears to be a better discriminative test in assessing airway function in asthmatic children, and may be a particularly useful tool in assessing asthmatics with normal FEV1. Thus, as has been reported many times, it appears that commonly used spirometric values are less useful in children than in adults and that other parameters of airways function may yield more relevant information.

\section{Asthma prevention and management}

The crucial question in asthma remains how to prevent its development. Thus, unravelling and assessing the potential impact of risk factors is mandatory, with subsequent intervention trials to see if avoidance of specific factors or targeted interventions can prevent disease. The Danish Copenhagen Studies on Asthma in Childhood (COPSAC) study linked maternal plasma vitamin D during pregnancy to wheeze during the first 6 yrs of life and described a nonsignificant inverse relationship [19]. A significant inverse association between plasma vitamin $\mathrm{D}$ in $4 \mathrm{yr}$ olds and asthma risk at that age was reported in the Dutch Prevention and Incidence of Asthma and Mire Allergy (PIAMA) study but this association was transient and plasma vitamin D levels at 4 yrs of age were not linked to asthma symptoms at age 8 yrs [20]. A casecontrol study based on observations from the Dutch KOALA birth cohort study reported that vitamin D supplementation during infancy was associated with a $50 \%$ reduction in asthma risk at 6-7 yrs of age [21]. The authors concluded that the use of vitamin D supplements in infancy may decrease asthma risk in later childhood, in line with several studies showing beneficial effects of increased vitamin D levels in reducing wheeze and atopic eczema [22]. Similarly, reduced vitamin D levels were associated with increased requirement for corticosteroid treatment [23], as well as with an increased risk of severe asthma exacerbations in the Childhood Asthma Management Program (CAMP) study [24]. Whether or not vitamin D supplementation can be a significant preventive strategy for asthma and/or other allergic diseases remains to be tested in randomised clinical trials; however, it is interesting that a randomised trial demonstrated a reduced risk of influenza A in children taking vitamin D supplements [25].

Management of severe asthma remains difficult since we lack good criteria for understanding and classifying children at different ages with severe disease; since they are relatively few ( $\sim 4.5 \%$ of asthmatic children [26]), few centres on their own will have large populations to test asthma management. Thus, a common international approach is mandatory. This is discussed in the series of papers on problematic severe asthma from the GA ${ }^{2} L E N$ group of paediatricians throughout Europe $[15,16,27]$. At the ERS Congress, a study from Texas, USA, in collaboration with Novartis, was presented suggesting that the number needed to treat to prevent 1 exacerbation per year with omalizumab was 1.7-1.8 in 576 6-12-yr-old children with inadequately controlled asthma [28]. Improvements in asthma symptoms, quality of life and asthma exacerbations were also found in children with severe asthma after a 16-week open label, nonrandomised trial in London, UK [29]. Thus, antiimmunoglobulin-E treatment has gained support in children with severe asthma associated with allergic inflammation $[30,31]$, but its definitive role in severe childhood asthma needs further evaluation. Other aspects that were debated and will receive more attention in the years to come are home monitoring and patients' self-management. With the ever increasing costs to society by allergic diseases in general, and asthma in particular, there is an urgent need to evaluate optimal patient management strategies, including new virtual monitoring schemes.

\section{CYSTIC FIBROSIS}

\section{Therapeutic strategies}

New therapeutic strategies addressing the cystic fibrosis transmembrane conductance regulator (CFTR) or other chloride channels are emerging. The CFTR potentiator VX-770 has shown to be efficacious in patients with the G551D mutation, in whom CFTR is present at the cell surface, but does not open properly. A phase II study demonstrated reduced sweat chloride concentrations, improved chloride secretion in nasal epithelium and improvements in lung function [32, 33]. New evidence was presented that denufosol, an activator of an alternative chloride channel, also inhibits sodium absorption, an important component of cystic fibrosis (CF) pathophysiology [34]. A subgroup analysis for the first phase III study demonstrated larger lung function improvements for patients on limited concurrent therapy as well as for adolescent patients [35]. More information from large clinical trials will become available for both compounds in 2011.

\section{Imaging and lung function}

Imaging techniques have become an area of active research and longitudinal computed tomography (CT) data from Australia now shows evidence for progression of bronchiectasis in early childhood [36]. Positron emission tomography scanning is currently being explored as a novel modality to capture airway inflammation [37]. Radiation exposure for both techniques limits their widespread use, but magnetic resonance imaging technology is constantly improving and could 
potentially become an alternative imaging technique to capture lung disease [38].

More data support the use of LCI as a sensitive measure of lung disease. LCI was reported to be abnormal in 3-month-old CF infants diagnosed by newborn screening [39]. These results contrast with those previously reported by the Melbourne group [40], and have implications for the understanding and treatment of early CF lung disease. In addition, poor nutritional status in infancy was associated with an increased LCI [41]. Improvement of the LCI was demonstrated in children with normal FEV1 after dornase alfa administration, further supporting its use in interventional studies [42, 43]. While uncertainty exists on defining the threshold for a significant change in the LCI, short-term variability of the technique in both CF patients and controls was shown to be relatively low [44]. Multiple devices to measure LCI have entered the market and comparative studies with the current "gold standard", mass spectrometry, are crucial for understanding their validity [45].

\section{Airway infection}

Airway infection is usually dominated by bacteria and molecular techniques demonstrate a rather complex bacterial microbiome in CF airways [46]. The contribution and significance of viral infections remains poorly defined. MALFROOT et al. [47] reported isolation of viruses in one-third of exacerbations, which may be an underestimation as rhinovirus was not included in the analysis. Using bronchial epithelial cells from young CF children, STICK et al. [48] and FoO et al. [49] demonstrated a combination of decreased apoptosis, increased interleukin (IL)-8 response and decreased interferon (IFN)- $\gamma$ concentrations after in vitro rhinoviral infection, suggesting a dysregulated inflammatory response in CF epithelium. Interestingly, while an independent study confirmed a decreased IFN- $\gamma$ response, the pro-inflammatory cytokine response was similar in CF and non-CF human bronchial epithelial cells $[50,51]$. Overall, these data highlight the difficulties of modelling the in vivo response in vitro; a problem that has plagued $\mathrm{CF}$ researchers over the last decades.

Increasingly, evidence suggests that Aspergillus may play a role in CF patients beyond allergic bronchopulmonary aspergillosis (ABPA) [52, 53]. Aspergillus was described as the most prominent organism in bronchoalveolar lavage (BAL) fluids from CF patients in one series and BAL positivity for Aspergillus was linked to increased airway inflammation in another study [54, 55]. In addition, sensitisation to Aspergillus, independent of ABPA, was found to be linked to poorer lung function [56]. While its pharmacokinetics are now better defined in CF patients, the benefit of antifungal therapy still remains controversial [57].

\section{PAEDIATRIC RESPIRATORY EPIDEMIOLOGY Paediatric Respiratory Epidemiology Award}

The three paediatric respiratory epidemiology abstracts scored most highly by the reviewers at the 2010 ERS Congress were awarded prizes. The first, a study from Southampton, UK, described associations between maternal plasma fatty acid concentrations at 34 weeks' gestation and asthma and allergy outcomes at age 6 yrs; plasma phosphatidylcholine arachidonic acid was positively associated with skin prick reactivity and increased risk for atopic wheeze while $\alpha$-linolenic and eicosapentanoic acid were inversely associated with diagnosed asthma [58]. The second award went to the longitudinal Avon Longitudinal Study of Parents and Children (ALSPAC) cohort based in Bristol, UK, in which the relationship between swimming pool attendance and asthma was explored; previous cross-sectional studies have reported a positive association, but the ALSPAC group reported swimming pool attendance was associated with a $50 \%$ reduction in asthma prevalence and higher lung function [59]. The third award went to the Bern/Leicester collaboration who validated the Tucson Asthma Predictive Index (API) in their population as a tool to predict the outcome of early wheeze; the sensitivity for asthma at age $10 \mathrm{yrs}$, based on information at $3 \mathrm{yrs}$ of age, was $26 \%$ for the loose API and 37\% for the stringent API and these relatively low numbers are consistent with those reported for the Tucson population [60].

\section{International Study of Asthma and Allergies in Childhood}

The International Study of Asthma and Allergies in Childhood (ISAAC) methodology continues to be applied to populations around the world and the results highlight geographical variations. For example, in Romanian children the prevalence of asthma is lower in urban areas $(2.1 \%)$ compared to the prevalence across the whole of Romania (3.2\%) [61]. In Chile, by contrast, the prevalence of asthma was $40 \%$ lower in rural areas than in urban areas [62]. In Cypriot children, the prevalence of asthma symptoms increased between 2000 and 2008 and this rise was $40 \%$ greater in rural areas than in urban areas [63]. The consistency of methodologies between centres gives assurance that these apparently conflicting results may be genuine but the underlying mechanisms are yet to be described.

\section{Development of asthma}

Mechanisms for the development of asthma are known to be active during early life and vitamin $\mathrm{D}$ has been the focus of much research (see previously). While none of the studies on vitamin D and asthma development prove causation, they add to the burden of evidence supportive of a "dietary hypothesis" for asthma causation. Other early exposures which might influence childhood respiratory outcomes include maternal paracetamol and alcohol ingestion and antibiotic use during infancy. The effect of maternal paracetamol may be modified by maternal antioxidant genes [64]. Even low quantities of maternal alcohol during pregnancy were linked with reduced fetal size and childhood lung function but not increased asthma symptoms [65]. A systematic review reporting the association between antibiotic use during infancy and subsequent asthma was of borderline significance once reverse causation was considered [66].

\section{Other topics}

While asthma was again the dominant theme among abstracts, there were many other important paediatric conditions covered. A rapid increase in empyema prevalence was described in the UK and a group from Newcastle upon Tyne, UK, observed that some of this increase may be attributable to increasing pneumonia prevalence but other factors may also be at play [67]. The H1N1 pandemic affected us all in 2009/2010 and the management of suspected H1N1 infection in the UK 
was mostly found to be not consistent with guidelines but not to the detriment of children's health [68].

\section{PAEDIATRIC RESPIRATORY INFECTION AND IMMUNOLOGY}

Community-acquired pneumonia and recurrent pneumonia Despite widespread vaccination, Streptococcus pneumoniae is still a frequent cause of community-acquired pneumonia (CAP) in childhood. Even new vaccines do not cover all serotypes [69]. Thus, it is important to identify the S. pneumoniae serotypes causing pneumonia in order to differentiate failure of vaccination from pneumonia caused by serotypes not covered by the vaccines. Blood cultures yield positive results in only $10 \%$ of cases. MALFrOOT et al. [70] showed that serotype specific serology may be helpful in identifying the aetiology of pneumococcal pneumonia in patients with negative blood cultures. According to a retrospective study from Israel, penicillin still appears to be the first-choice treatment of uncomplicated CAP in childhood [71]. The increasing prevalence of pneumonias complicated by parapneumonic effusions does not lead to long-term sequelae in the majority of children. 2 yrs after a complicated pneumonia, $75 \%$ of the tested schoolchildren showed normal lung function and exercise capacity; of those with decreased exercise capacity all but one had concurrent asthma [72].

Recurrent pneumonia is a frequent finding in children, but studies elucidating the underlying causes are rare. Two studies showed divergent results. In a study from the Netherlands, the main causes of recurrent pneumonia in 62 children were reflux or aspiration, primary or acquired immunodeficiency, congenital heart disease or pre-existing lung disease. Asthma was not diagnosed as an underlying cause in any of these children; in one-third of the children no underlying cause could be identified [73]. In contrast, in a study from Brazil including 46 children with recurrent pneumonia, asthma was diagnosed in $78 \%$ and thus considered the most frequent underlying cause [74].

\section{Other topics}

Little is known about how to best follow up pulmonary involvement in children with immunodeficiency. vAN DE VEN et al. [75] showed that, compared to lung function tests and chest radiographs, high-resolution CT scanning is the most sensitive tool to detect pulmonary disease and can be used to differentiate between structural and interstitial lung disease in children with common variable immunodeficiency.

In 2009, a new virus, influenza A/H1N1, caused an influenza pandemic, with children being at risk of developing complications. A few studies have shown that neurodevelopmental disorders, underlying diseases such as diabetes or $\mathrm{CF}$, and young age were the main risk factors for a severe course of H1N1 influenza with secondary bacterial pneumonia, admission to an intensive care unit and deaths [76, 77]. In a case series from Serbia, all asthmatic children admitted to hospital with H1N1 developed pneumonia compared with only $40 \%$ of children without asthma [78].

Variation in the management of acute viral bronchiolitis and lack of clear evidence for any single approach led to a systematic review of 48 randomised controlled trials in children aged $<24$ months with a first episode of bronchiolitis, comparing bronchodilators or corticosteroids (alone or combined) with placebo or other interventions. The authors reported that the use of epinephrine in outpatients led to reduced admissions, but no evidence was found for the use of other bronchodilators or corticosteroids [79].

In 2007, BISGAARD et al. [80] published the observation that bacterial colonisation of the neonatal airways with pathogenic strains of Haemophilus influenzae, S. pneumoniae and Moraxella catarrhalis is associated with recurrent wheeze and asthma in early childhood. In a prospective study to further elucidate the mechanisms underlying this observation it was found that neonates colonised with these bacteria had upregulated nasal epithelial lining fluid levels of IL-2, IL-10, IL-13 and CXCL8 (IL-8) compared to the neonates without such a colonisation, suggesting that colonisation is associated with a subclinical nasal inflammatory response preceding the development of atopic disease [81].

\section{NEONATOLOGY AND PAEDIATRIC INTENSIVE CARE Neonatology}

Neonatal resuscitation is an area attracting considerable attention at present. New techniques have allowed imaging of the very first breaths of life [82] and an international study has shown the importance of early sustained lung inflation on subsequent morbidity [83]. Concerns centre both on the amount of oxygen that is needed during resuscitation, as well as the pressures used to ventilate during the first minutes of life [84]. Data from Kelm et al. [85] suggest that even if experienced operators are asked to manually ventilate a manikin (set to simulate a 1,000 $\mathrm{g}$ baby), the pressures and volumes delivered can vary considerably depending on the equipment used. This is important as other studies have demonstrated that alveolar volume/tidal volume ratios increase with increasing gestational age [86]. Consequently, ventilator settings need to take account of maturity as well as weight to avoid potential volutrauma.

Rescue steroids, administered antenatally to females in preterm labour, have been shown to improve neonatal outcome and increase lung compliance. However, there have been clinical concerns that they may also have an adverse effect on long-term lung growth. In a study of 109 babies whose mothers received rescue steroids, lung function at 12-24 months has been shown to be no different from a placebo group [87].

\section{Paediatric intensive care}

In paediatric intensive care units, noninvasive techniques for respiratory support are evolving. Recent data has shown that noninvasive ventilation can be used successfully in children presenting with acute respiratory failure [88]. In a study from Australia, FOSTER et al. [89] have shown that administration of high-flow oxygen (up to $2 \mathrm{~mL} \cdot \mathrm{kg}^{-1} \cdot \mathrm{min}^{-1}$ ) can avoid the need for intubation. In their study of almost 200 patients, the rate of intubation in the bronchiolitis group (110 patients) was down to $2 \%$. Some concerns over the control of airway pressure with this technique do remain, but the reduction in invasive ventilation is encouraging.

As well as noninvasive treatment, noninvasive assessment of lung function is becoming a reality. UsHER-SMITH et al. [90] have shown excellent early results of a noninvasive light-based 
technique (structured light plethysmography) for evaluating lung function, which allows reconstruction of thoracic and abdominal volumes in real time from three-dimensional reconstruction of a video. A chequered pattern of light is shone on to the chest wall and filmed from two angles, with an entirely non-touch technique. WALTER et al. [91] have also recently evaluated a new technique, using a volumetric vest in infants. In a group of 20 infants with and without bronchopulmonary dysplasia, the vest differentiated patterns of breathing (such as inspiratory time/expiratory time ratios) between groups. Electrical impedance tomography (EIT) has been available for longer. HuMPHREYs et al. [92] have shown acute changes in lung volume during elective intubation. In a group of 38 children undergoing induction of anaesthesia prior to cardiac surgery, functional residual capacity dropped during the period of intubation, and mechanical ventilation redistributed ventilation towards the anterior parts of the lung.

\section{PAEDIATRIC BRONCHOLOGY \\ Technique and indications}

Flexible endoscopy of the airway has become an increasingly important tool for evaluating respiratory disorders in children and can also be useful in therapy. The technique has continuously improved and numerous publications have described indications, methods, diagnostic utility and safety [93]. In a series of 316 diagnostic flexible bronchoscopies in 305 Greek children, KYRVASSILIS et al. [94] showed that flexible bronchoscopy is a safe procedure, without major important side-effects and with a diagnostic yield of $75 \%$. In their experience, stridor was the indication with the highest diagnostic yield and chronic cough the indication with the lowest. The availability of smaller bronchoscopes has expanded the range and indications for this technique in neonates and premature babies. In a group of 123 neonates, FLORES-HERNÁNDEZ et al. [95] showed that flexible bronchoscopy is also safe in this age group; the main indications included persistent/recurrent atelectasis, stridor and assessment of congenital abnormalities of the tracheobronchial tree. ANTÓN-PACHECO et al. [96] also reported flexible bronchoscopy to be an important diagnostic tool in the management of children with craniofacial syndromes. They frequently encountered airway anomalies in patients with severe craniofacial syndromes, especially in those with respiratory symptoms [96]. Another important diagnostic application of flexible bronchoscopy is the evaluation of swallowing dysfunction in infants with suspected aspiration. In a study evaluating 94 patients, PEÑA et al. [97] showed that fibreoptic endoscopic evaluation of swallowing provides important diagnostic information to guide treatment in children with dysphagia and aspiration.

\section{Special procedures}

Several special procedures can be performed through the working channel of the flexible bronchoscope [93]. BAL is particularly useful to increase the diagnostic yield of flexible bronchoscopy, and is routinely performed during flexible bronchoscopy for clinical and research purposes [98]. MAMMAS et al. [99] evaluated the presence of S. pneumoniae in bronchial lavage samples from 65 non-CF immunocompetent children with protracted purulent bronchitis. They found that the most prevalent serotypes were 1,18C,19A and 19F, all sensitive to amoxicillin-clavulanic acid, and concluded that further data on serotype distribution would help to guide appropriate pneumococcal conjugate vaccine formulation. A useful research application of BAL is to obtain samples from children with severe asthma to evaluate the underlying inflammatory processes. In a study from London, UK, including 72 children with severe asthma, ULLMANN et al. [100] found a poor relationship between blood markers of inflammation and local pulmonary markers as obtained by measurement of FeNO, sputum induction, BAL and endobronchial biopsy. Thus, they concluded that in order to characterise children with severe asthma accurately, BAL samples and endobronchial biopsy specimens are required.

Therapeutic BAL can be indicated for removing airways material. In a case report, CARO-AGUILERA et al. [101] demonstrated the critical role of flexible bronchoscopy in the diagnosis and treatment of a patient with plastic bronchitis, an unusual condition characterised by the development of thick casts in the tracheobronchial tree. Congenital tracheooesophageal fistula may be difficult to diagnose and manage and the recurrence rate reaches $10 \%$ after surgical treatment. A reasonable alternative to operative closure is to close the fistula from the oesophagus via a flexible bronchoscope with a two-

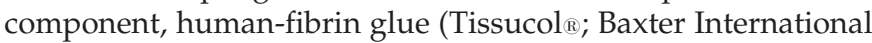
Inc., Deerfield, IL, USA) [102].

Foreign body removal from the tracheobronchial tree is an important clinical application of rigid bronchoscopy in children. However, the most suitable technique for foreign body extraction remains controversial. Most physicians recommend that, in the presence of a radiopaque foreign body or asphyxia, removal of the foreign body should only be attempted with a rigid bronchoscope [103]. In a small series of seven children, PAVLOV et al. [104] reported the successful extraction of foreign bodies with a flexible bronchoscope, demonstrating that in selected cases foreign bodies can also be safely extracted with this technique.

\section{PAEDIATRIC RESPIRATORY PHYSIOLOGY}

There is increasing interest in the early life origins of adult lung disease, but there are limited functional data available. TRAN et al. [105] presented the long-term follow-up of the 1957 Melbourne childhood asthma cohort. At 50 yrs, the 198 subjects were classified as normal, asthma, chronic obstructive pulmonary disease (COPD) and overlap, based on spirometry, diffusing capacity of the lung for carbon monoxide and multiple-breath washout (MBW) measurements. Of the 149 with childhood asthma, 15\% had COPD and $8 \%$ had overlapping symptoms of both asthma and COPD. Of the 35 who had severe childhood asthma or persistent asthma, $43 \%$ and $15 \%$, respectively, had COPD. These results demonstrate tracking of lung function from childhood to $50 \mathrm{yrs}$ of age and that COPD in middle age is a common consequence of severe asthma in childhood [105].

The use of the MBW technique to quantify ventilation inhomogeneity in paediatric lung disease and development is now well established [106]. At the 2010 ERS Congress a number of research groups reported data from alternative techniques to quantify inhomogeneity. PHAM et al. [107] reported EIT recordings in spontaneously breathing term infants measured soon after birth and again at 3 and 6 months 
of age. At all these ages the authors demonstrated that the dependent lung showed earlier filling and better ventilation than the non-dependent lung.

SINGER et al. [108] reported a modified tidal single breath washout (SBW) test, using a double tracer gas and a molar mass analyser. The test was demonstrated to be feasible and to show differences between children with CF and healthy controls. More detailed comparative studies with MBW and traditional SBW measurements are now required.

Lo MAURO et al. [109] employed opto-electronic plethysmography to quantify the inspiration, and the compressive and expiratory phases of cough in 74 children and adolescents with Duchenne muscular dystrophy (DMD) and age-matched controls. Adolescents with DMD demonstrated reduced chest wall volume expansion and reduced peak expiratory flow compared to control adolescents, while younger children with DMD showed normal results.

\section{STATEMENT OF INTEREST}

Statements of interest for K.C. Lødrup Carlsen and F. Ratjen can be found at www.erj.ersjournals.com/site/misc/statements.xhtml

\section{REFERENCES}

1 Carraro S, Cogo PE, Isak I, et al. EIA and GC/MS analysis of 8-isoprostane in EBC of children with problematic asthma. Eur Respir J 2010; 35: 1364-1369.

2 Carraro S, Rezzi S, Reniero F, et al. Metabolomics applied to exhaled breath condensate in childhood asthma. Am J Respir Crit Care Med 2007; 175: 986-990.

3 Caballero Balanzá S, Martorell Aragonés A, Cerdá Mir JC, et al. Leukotriene B4 and 8-isoprostane in exhaled breath condensate of children with episodic and persistent asthma. I Investig Allergol Clin Immunol 2010; 20: 237-243.

4 Robroeks CM, Rijkers GT, Jöbsis Q, et al. Increased cytokines, chemokines and soluble adhesion molecules in exhaled breath condensate of asthmatic children. Clin Exp Allergy 2010; 40: 77-84.

5 van der Schee MP, van Amelsfoort RM, Regenboog M, et al. Assessment of virus-induced wheeze by exhaled breath molecular profiling in pre-school children, the EUROPA-study. Eur Respir J 2010; 36: Suppl. 54, 367s.

6 Carraro S, Giordano G, Stocchero M, et al. Breathomics for characterizing asthma phenotypes in children. Eur Respir J 2010; 36: Suppl. 54, 367s.

7 Bischoff AL, Holmberg M, van der Schee MP, et al. Volatile organic compounds assessment of asthma in children. Eur Respir J 2010; 36: Suppl. 54, 366s-367s.

8 Dallinga JW, Robroeks CM, van Berkel JJ, et al. Volatile organic compounds in exhaled breath as a diagnostic tool for asthma in children. Clin Exp Allergy 2010; 40: 68-76.

9 Sachs-Olsen C, Sanak M, Lang AM, et al. Eoxins: a new inflammatory pathway in childhood asthma. J Allergy Clin Immunol 2010; 126: 859-867.e9.

10 Franklin P, Hall G, Stavreska V, et al. Infant exhaled nitric oxide does not identify wheezy children by age of seven years. Eur Respir J 2010; 36: Suppl. 54, 367s-368s.

11 Chawes BLK, Buchvald F, Bischoff AL, et al. Elevated exhaled nitric oxide in healthy neonates precedes transient early but not persistent wheeze. Eur Respir J 2010; 36: Suppl. 54, 368s.

12 Stanojevic S, Wade A, Cole TJ, et al. Spirometry centile charts for young Caucasian children: the Asthma UK Collaborative Initiative. Am J Respir Crit Care Med 2009; 180: 547-552.
13 Cole TJ, Stanojevic S, Stocks J, et al. Age- and size-related reference ranges: a case study of spirometry through childhood and adulthood. Stat Med 2009; 28: 880-898.

14 Quanjer PH, Borsboom GJ, Kivastik J, et al. Cross-sectional and longitudinal spirometry in children and adolescents: interpretative strategies. Am J Respir Crit Care Med 2008; 178: 1262-1270.

15 Hedlin G, Bush A, Lødrup Carlsen K, et al. Problematic severe asthma in children, not one problem but many: a GA ${ }^{2} \mathrm{LEN}$ initiative. Eur Respir J 2010; 36: 196-201.

16 Lødrup Carlsen KC, Hedlin G, Bush A, et al. Assessment of problematic severe asthma in children. Eur Respir J 2011; 37: 432-440.

17 Lang AM, Konradsen J, Carlsen $\mathrm{KH}$, et al. Identifying problematic severe asthma in the individual child - does lung function matter? Acta Paediatr 2010; 99: 404-410.

$18 \mathrm{O}^{\prime}$ Reilly R, Irving S, Gupta A, et al. Is lung clearance index a better marker of abnormal airway function than FEV1 in children with asthma? Eur Respir J 2010; 36: Suppl. 54, 467s.

19 Pedersen L, Jensen PF, Heickendorff L, et al. Maternal vitamin D during pregnancy and recurrent wheeze in childhood. Eur Respir J 2010; 36: Suppl. 54, 677s-678s.

20 Bekkers MBM, van Oeffelen LAM, Haveman-Nies A, et al. Serum micronutrient concentrations and childhood asthma. Eur Respir J 2010; 36: Suppl. 54, 677s.

21 Mommers M, Penders J, Thijs C. Vitamin D supplements use in infancy is inversely associated with asthma at school-age. Eur Respir J 2010; 36: Suppl. 54, 366s.

22 Miyake Y, Sasaki S, Tanaka K, et al. Dairy food, calcium and vitamin $\mathrm{D}$ intake in pregnancy, and wheeze and eczema in infants. Eur Respir J 2010; 35: 1228-1234.

23 Searing DA, Zhang Y, Murphy JR, et al. Decreased serum vitamin $\mathrm{D}$ levels in children with asthma are associated with increased corticosteroid use. J Allergy Clin Immunol 2010; 125: 995-1000.

24 Brehm JM, Schuemann B, Fuhlbrigge AL, et al. Serum vitamin D levels and severe asthma exacerbations in the Childhood Asthma Management Program study. J Allergy Clin Immunol 2010; 126: 52-58.e5.

25 Urashima M, Segawa T, Okazaki M, et al. Randomized trial of vitamin D supplementation to prevent seasonal influenza A in schoolchildren. Am J Clin Nutr 2010; 91: 1255-1260.

26 Lang A, Carlsen $\mathrm{KH}$, Haaland G, et al. Severe asthma in childhood: assessed in 10 year olds in a birth cohort study. Allergy 2008; 63: 1054-1060.

27 Bush A, Hedlin G, Carlsen KH, et al. Severe childhood asthma: a common international approach? Lancet 2008; 372: 1019-1021.

28 Lanier B, Fowler Taylor A, Fernandez Vidaurre C, et al. Number needed to treat (NNT) to prevent one exacerbation per year with omalizumab (OMA) in children with inadequately controlled allergic (IgE-mediated) asthma. Eur Respir J 2010; 36: Suppl. 54, 472s.

29 Bossley C, Gupta A, Ullman N, et al. Omalizumab in children with severe asthma (SA): which parameters improve after a 16 week trial? Eur Respir J 2010; 36: Suppl. 54, 472s.

30 Massanari M, Milgrom H, Pollard S, et al. Adding omalizumab to the therapy of adolescents with persistent uncontrolled moderate-severe allergic asthma. Clin Pediatr (Phila) 2009; 48: 859-865.

31 Kulus M, Hébert J, Garcia E, et al. Omalizumab in children with inadequately controlled severe allergic (IgE-mediated) asthma. Curr Med Res Opin 2010; 26: 1285-1293.

32 Donaldson S, Accurso F, Rowe S, et al. Improved CFTR and lung function with VX-770, a novel investigational potentiator of CFTR, in subjects with the G551D-CFTR mutation. Eur Respir J 2010; 36: Suppl. 54, 34s-35s.

33 Accurso FJ, Rowe SM, Clancy JP, et al. Effect of VX-770 in persons with cystic fibrosis and the G551D-CFTR mutation. N Engl J Med 2010; 363: 1991-2003. 
34 Stutts MJ, Cowlen MS, Okada SF, et al. Denufosol: A novel ion channel regulator and investigational early-intervention therapy for cystic fibrosis. Eur Respir J 2010; 36: Suppl. 54, 695 s.

35 Accurso F, Navratil T, Schaberg A, et al. Denufosol targets small airways and elicits meaningful improvements in mild cystic fibrosis (CF) patients on minimal pharmacotherapy. Eur Respir J 2010; 36: Suppl. 54, 35s.

36 Mott L, Murray C, de Klerk N, et al. Progression of early CTdetected structural lung damage in cystic fibrosis. Eur Respir $J$ 2010; 36: Suppl. 54, 35s.

37 Amin R, Charron M, Grinblat L, et al. FDG-PET imaging detects inflammatory changes in pediatric cystic fibrosis patients after treatment for a pulmonary exacerbation. Eur Respir J 2010; 36: Suppl. 54, 35s.

38 Mennini ML, Fraioli F, Serra G, et al. Role of chest magnetic resonance imaging (MRI) in the assessment and follow up of patients with cystic fibrosis (CF). Eur Respir J 2010; 36: Suppl. 54, $744 \mathrm{~s}$.

39 Hoo AF, Chudleigh J, Prasad A, et al. Is lung function diminished by 3 months of age in infants with cystic fibrosis (CF) diagnosed by newborn screening (NBS)? Eur Respir J 2010; 36: Suppl. 54, 1016s.

40 Linnane BM, Hall GL, Nolan G, et al. Lung function in infants with cystic fibrosis diagnosed by newborn screening. Am J Respir Crit Care Med 2008; 178: 1238-1244.

41 Zirbes J, Milla C. Lung clearance index (LCI) and nutritional parameters in infants with cystic fibrosis. Eur Respir J 2010; 36: Suppl. 54, 870s.

42 Amin R, Subbarao P, Lou $W$, et al. The effect of rhDNase on ventilation inhomogeneity in patients with cystic fibrosis. Eur Respir J 2010; 36: Suppl. 54, 631s.

43 Amin R, Subbarao P, Jabar A, et al. Hypertonic saline improves the LCI in paediatric patients with CF with normal lung function. Thorax 2010; 65: 379-383.

44 Lindblad A, Gustafsson P. Short term variability of lung clearance index in CF and healthy controls. Eur Respir J 2010; 36: Suppl. 54, 631s-632s.

45 Macleod K, Irving S, Horsley A, et al. Validation of a modified photo-acoustic gas analyser for in vitro multiple breath washout in young children. Eur Respir J 2010; 36: Suppl. 54, 703s.

46 Duff R, Simmonds N, Davies J, et al. Molecular detection of complex microbial communities in sputa of patients with cystic fibrosis and non cystic fibrosis bronchiectasis. Eur Respir J 2010; 36: Suppl. 54, 629s.

47 Malfroot A, De Wachter E, Van Ginderdeuren F, et al. Viral diagnosis in respiratory exacerbations in CF. Eur Respir J 2010; 36: Suppl. 54, 34s.

48 Stick S, Kicic A, Sutanto E. Dysregulated inflammatory and apoptotic responses to human rhinovirus in primary airway cells from young patients with cystic fibrosis. Eur Respir J 2010; 36: Suppl. 54, 34s.

49 Foo CJ, Sutanto EN, Kicic A, et al. Elucidating the cellular responses of healthy and cystic fibrosis (CF) airway epithelial cells in response to non-viral stimuli and human rhinoviral (HRV) infection. Eur Respir J 2010; 36: Suppl. 54, 696s.

50 Kieninger E, Vareille M, Latzin $\mathrm{P}$, et al. Inflammatory response upon viral infection in cystic fibrosis airway epithelial cells. Eur Respir J 2010; 36: Suppl. 54, 34s.

51 Vareille M, Kieninger E, Mühlemann K, et al. Deficient innate immune antiviral response to infection with rhinoviruses in cystic fibrosis airway epithelial cells. Eur Respir J 2010; 36: Suppl. $54,34 \mathrm{~s}$.

52 Amin R, Dupuis A, Aaron SD, et al. The effect of chronic infection with Aspergillus fumigatus on lung function and hospitalization in patients with cystic fibrosis. Chest 2010; 137: 171-176.
53 Shoseyov D, Brownlee KG, Conway SP, et al. Aspergillus bronchitis in cystic fibrosis. Chest 2006; 130: 222-226.

54 Davidson N, Blain A, McKean M, et al. Aspergillus is now the dominant organism isolated from bronchoalveolar lavage in children with CF children in north east England. Eur Respir J 2010; 36: Suppl. 54, 630s.

55 Gangell C, Samantha G, Tonia D, et al. Inflammatory responses to individual organisms in the lungs of children with cystic fibrosis. Eur Respir J 2010; 36: Suppl. 54, 696s.

56 Peetermans M, Goeminne P, De Boeck K, et al. Impact of sensitization to Aspergillus fumigatus on lung function in cystic fibrosis. Eur Respir J 2010; 36: Suppl. 54, 629s.

57 Clifton I, Whitaker P, Metcalfe R, et al. Pharmacokinetics of oral voriconazole in adults with cystic fibrosis. Eur Respir J 2010; 36 Suppl. 54, 631s.

58 Pike K, Lucas J, Godfrey K, et al. Prenatal polyunsaturated fatty acid exposure is associated with childhood atopy and wheeze. Eur Respir J 2010; 36: Suppl. 54, 11s.

59 Font-Ribera L, Villanueva CM, Nieuwhenhuijsen MJ, et al. Swimming pool attendance, asthma and allergies in the ALSPAC child cohort. Eur Respir J 2010; 36: Suppl. 54, 676s-677s.

60 Leonardi NA, Spycher BD, Beardsmore CS, et al. Validating the Tucson asthma predictive index in an independent cohort. Eur Respir J 2010; 36: Suppl. 54, 11s.

61 Gheonea C, Plesca DA, Dumitrescu L, et al. Asthma prevalence in children in Oltenia region (south-western Romania). Eur Respir J 2010; 36: Suppl. 54, 886s.

62 Calvo M, Kausel L, Boneberger A, et al. Asthma, rhinoconjunctivitis and eczema symptoms in children in urban and rural residential sectors. Valdivia, Chile. Eur Respir J 2010; 36: Suppl. $54,886 \mathrm{~s}$.

63 Kolokotroni O, Nicolaou N, Middleton N, et al. Trends in the prevalence of asthma and allergies in children residing in urban and rural areas in Cyprus. Eur Respir J 2010; 36: Suppl. 54, 885s-886s.

64 Shaheen S, Newson R, Ring S, et al. Association between prenatal paracetamol exposure and childhood asthma is modified by maternal antioxidant genotype. Eur Respir J 2010; 36: Suppl. 54, 10s-11s.

65 Turner S, Prabhu N, Smith N, et al. Maternal alcohol intake during pregnancy as a risk factor for childhood asthma. Eur Respir J 2010; 36: Suppl. 54, 678s.

66 Penders J, Thijs C, Kummeling I. The effect of reverse causation (RC) and confounding-by-indication $(\mathrm{CbI})$ on the association between infant antibiotic use and asthma risk - a systematic review and meta-analysis. Eur Respir J 2010; 36: Suppl. 54, 678s-679s.

67 Thomas M, Cliff D, Rushton S, et al. Trends in paediatric pneumonia and empyema in England 1997-2006. Eur Respir J 2010; 36: Suppl. 54, 11s.

68 Sen A, Nwokoro C, Aniapravan R, et al. Guideline adherence in the management of pandemic flu: from panic to pragmatic. Eur Respir J 2010; 36: Suppl. 54, 485s.

69 Vila-Corcoles A, Salsench-Serrano E, Guzman-Avalos J, et al. Streptococcus pneumoniae causing infection among children in the region of Tarragona (Spain): serotype coverage for the new conjugate vaccines. Eur Respir J 2010; 36: Suppl. 54, 978s.

70 Malfroot A, De Schutter I, Smet J, et al. Use of serotype specific serology (IgA and $\operatorname{IgG}$ ) in the aetiologic diagnosis of childhood pneumococcal pneumonia: first results from the pediatric pneumococcal pneumonia (3P) trial. Eur Respir J 2010; 36 Suppl. 54, 977s-978s.

71 Schejter YD, Cohen M, Kerem E. Management of community acquired pneumonia: a retrospective comparison of penicillin and cefuroxime. Eur Respir J 2010; 36: Suppl. 54, 978s-979s.

72 Kontouli K, Kirvassilis F, Hatziagorou E, et al. Parapneumonic effusions in children: evaluation of long-term effect on lung function and exercise capacity. Eur Respir J 2010; 36: Suppl. 54, 979s. 
73 Hoving P, Brand P. Underlying causes of recurrent pneumonia in children in the Netherlands. Eur Respir J 2010; 36: Suppl. 54, 625s.

74 Roncon R, Mansur L, Toro M, et al. Underlying causes of recurrent pneumonia in Brazilian children. Eur Respir J 2010; 36: Suppl. 54, 626s.

75 van de Ven A, Terheggen-Lagro S, van Konijnenburg DH, et al. A HRCT score to differentiate between structural and interstitial lung disease in children with common variable immunodeficiency (CVID). Eur Respir J 2010; 36: Suppl. 54, 625s.

76 Malfroot A, De Wachter E, Wybo I, et al. Influenza A/H1N1v infection in Belgian children with and without underlying risk factor. Eur Respir J 2010; 36: Suppl. 54, 624s.

77 Nenna R, De Angelis D, Soscia F, et al. 2009 influenza A (H1N1): hospitalization in a pediatric department in Rome. Eur Respir J 2010; 36: Suppl. 54, 624s.

78 Baumann S, Prodanovic S, Prodanovic J, et al. Influenza A H1N1 as a risk for asthma in children. Eur Respir J 2010; 36: Suppl. 54, 485s.

79 Hartling L, Fernandes RM, Bialy L, et al. Comparative effectiveness of steroids and bronchodilators for the acute care of bronchiolitis. Eur Respir J 2010; 36: Suppl. 54, 622s.

80 Bisgaard H, Hermansen MN, Buchvald F, et al. Childhood asthma after bacterial colonization of the airway in neonates. N Engl J Med 2007; 357: 1487-1495.

81 Følsgaard N, Chawes B, Edwards M, et al. Elevated nasal mucosal cytokines and chemokines in neonates with bacterial colonization of the airways. Eur Respir J 2010; 36: Suppl. 54, 623s.

82 Hooper SB, Kitchen MJ, Siew ML, et al. Imaging lung aeration and lung liquid clearance at birth using phase contrast X-ray imaging. Clin Exp Pharmacol Physiol 2009; 36: 117-125.

83 SUPPORT Study Group of the Eunice Kennedy Shriver NICHD Neonatal Research Network, Finer NN, Carlo WA, et al. Early CPAP versus surfactant in extremely preterm infants. $N$ Engl J Med 2010; 362: 1970-1979.

84 te Pas AB, Siew M, Wallace MJ, et al. Establishing functional residual capacity at birth: the effect of sustained inflation and positive end-expiratory pressure in a preterm rabbit model. Pediatr Res 2009; 65: 537-541.

85 Kelm M, Hartung J, Schmalisch G, et al. Integrated manometers in three manual ventilation devices used in neonatal resuscitation. Eur Respir J 2010; 36: Suppl. 54, 328s.

86 Neumann R, Larcombe A, Hall G, et al. Should ventilator target tidal volumes be adjusted for gestational age? Eur Respir J 2010; 36: Suppl. 54, 328s.

87 McEvoy C, Schilling D, Spitale P, et al. Pulmonary function and respiratory outcomes at 12-24 months in preterm infants randomized to a rescue course of antenatal steroids. Eur Respir J 2010; 36: Suppl. 54, 329s.

88 Muñoz-Bonet JI, Flor-Macián EM, Roselló PM, et al. Noninvasive ventilation in pediatric acute respiratory failure by means of a conventional volumetric ventilator. World J Pediatr 2010; 6: 323-330.

89 Foster K, Hough J, Pham TMT, et al. High flow nasal prong oxygen reduces the need for mechanical ventilation in bronchiolitic infants. Eur Respir J 2010; 36: Suppl. 54, 330s.

90 Usher-Smith J, Wareham R, Cameron J, et al. Structured light plethysmography in infants and children: a pilot study. Arch Dis Child 2009; 94: A38-A40.
91 Walter K, Olden C, Symes E, et al. Discrimination between neonates with and without lung disease using a volumetric vest system. Eur Respir J 2010; 36: Suppl. 54, 483s.

92 Humphreys S, Pham TMT, Schibler A. EIT to monitor the effect of induction of anaesthesia and intubation on end-expiratory level and regional ventilation distribution. Eur Respir J 2010; 36: Suppl. 54, 483s.

93 Midulla F, de Blic J, Barbato A, et al. Flexible endoscopy of paediatric airways. Eur Respir J 2003; 22: 698-708.

94 Kyrvassilis F, Gidaris D, Ventouri M, et al. Flexible fiberoptic bronchoscopy in Greek children. Eur Respir J 2010; 36: Suppl. 54, $6 \mathrm{~s}$.

95 Flores-Hernández SS, Gonzáles Flores MdL, Barragán MS, et al. Experience with bronchoscopy in neonates and premature infants. Eur Respir J 2010; 36: Suppl. 54, 490s.

96 Antón-Pacheco JL, Luna C, García-Hernández G, et al. The role of bronchoscopy in the management of patients with severe craniofacial syndromes. Eur Respir J 2010; 36: Suppl. 54, 5s.

97 Peña JA, de Borja Osona F, Gil JA, et al. Diagnosis and management of aspiration in children through fiberoptic endoscopic evaluation of swallowing. Eur Respir J 2010; 36: Suppl. 54, 5s.

98 De Blic J, Midulla F, Barbato A, et al. Bronchoalveolar lavage in children. Eur Respir J 2000; 15: 217-231.

99 Mammas I, Tzanakaki G, Makri A, et al. Streptococcus pneumoniae in bronchoalveolar lavage from non-CF children with protracted purulent bronchitis. Eur Respir J 2010; 36: Suppl. 54, 6 s.

100 Ullmann N, Bossley C, Fleming L, et al. Are blood inflammatory markers useful in characterising children with severe asthma (SA)? Eur Respir J 2010; 36: Suppl. 54, 6s.

101 Caro-Aguilera P, Pérez-Ruiz E, Pérez-Frías J, et al. Plastic bronchitis: a rare and serious complication after palliative surgery for cyanotic heart diseases. Eur Respir J 2010; 36: Suppl. 54, 489s.

102 Kovacs L, Dezsofi A, Krikovszky D, et al. Successful closure of secondary tracheo-esophageal fistula with Tissucol $\AA_{\circledR}$ tissue adhesive. Eur Respir J 2010; 36: Suppl. 54, 5s.

103 Midulla F, Guidi R, Barbato A, et al. Foreign body aspiration in children. Pediatr Int 2005; 47: 663-668.

104 Pavlov N, Dragišic-Ivulic S, Meštrovic J, et al. Flexible fiberoptic bronchoscopy and airway foreign body extraction in children. Eur Respir J 2010; 36: Suppl. 54, 488s.

105 Tran H, Tai A, Roberts M, et al. COPD: an outcome of childhood asthma? Eur Respir J 2010; 36: Suppl. 54, 1016s.

106 Beydon N, Davis SD, Lombardi E, et al. An official American Thoracic Society/European Respiratory Society statement: pulmonary function testing in preschool children. Am J Respir Crit Care Med 2007; 175: 1304-1345.

107 Pham TMT, Yuill M, Dakin C, et al. Regional ventilation distribution in the first six months of life. Eur Respir J 2010; 36: Suppl. 54, 1015s.

108 Singer F, Stern G, Thamrin C, et al. Single breath washout of double tracer gas in children with and without cystic fibrosis. Eur Respir J 2010; 36: Suppl. 54, 1015s.

109 Lo Mauro A, D’Angelo MG, Romei M, et al. Chest wall kinematics during cough in Duchenne muscular dystrophy (DMD). Eur Respir J 2010; 36: Suppl. 54, 1015s-1016s. 